\title{
Screening of the mitochondrial A1555G mutation in patients with sensorineural hearing loss
}

\section{Luciano Pereira Maniglia ${ }^{1}$, Bruna Carolina Lemos Moreira ${ }^{2}$, Magali Aparecida Orate Menezes da Silva $a^{3}$, Vânia Belintani Piattó, José Victor Maniglia ${ }^{5}$}

Keywords: aminoglycosides, hearing loss, mitochondrial DNA, mutation.

\section{Summary}

\begin{abstract}
$\mathrm{T}$
he $\mathrm{A} 1555 \mathrm{G}$ mitochondrial mutation is the main alteration associated with aminoglycoside-induced deafness. Aim: to investigate the prevalence of the $\mathrm{A} 1555 \mathrm{G}$ mutation in patients sensorineural hearing loss patients with and without aminoglycosides antibiotic use. Material and Method: a study of 27 cases with deafness as the sample, and 100 neonates with normal hearing as the control group. DNA was extracted from blood leukocyte samples, and specific oligonucleotide primers were designed to amplify the cytochrome $\mathrm{b}$ gene and the region which encloses the A1555G mutation of the mitocondrial DNA using the polymerase chain reaction and restriction fragment length polymorphism. Design: a crosssectional case study. Results: a region of the cytochrome $\mathrm{b}$ gene was amplified and the presence of the mtDNA was confirmed in all of the 127 cases. The A1555G mutation was not found in any of the 27 patients with hearing loss or the control group with 100 neonates. Conclusion: the results agree with studies stating that the A1555G mutation is not prevalent in the Americas. There is interest in establishing the real prevalence of this mutation and to investigate other mutations that may cause hearing loss, associated or not with the use of aminoglycosides, in the Brazilian population.
\end{abstract}

\footnotetext{
${ }^{1}$ Master's degree student, faculty member of the Otorhinolaryngology and Head \& Neck Surgery Department, Medical School, S. J. Rio Preto, SP, FAMERP. ${ }^{2}$ Medical student, Medical School, São José do Rio Preto, SP, FAMERP.

${ }^{3}$ Master's degree; head of the Speech Therapy Unit, Otorhinolaryngology and Head \& Neck Surgery Department, Medical School, S. J. Rio Preto, SP, FAMERP. ${ }^{4}$ Doctor, Adjunct professor.

${ }^{5}$ Livre-docente (habilitation) professor, head of the Otorhinolaryngology and Head \& Neck Surgery Department, Medical School, S. J. Rio Preto, SP, FAMERP. Medical School, São José do Rio Preto, SP, FAMERP.

Address for correspondence: Vânia Belintani Piatto - Rua Santina Figliagi Ceccato 450 ap. 23-A São José do Rio Preto SP $15035-180$ Telephone: (0xx17) 3201-5747 - E-mail: vbpiatto@gmail.com ou vabp@ig.com.br BIC - FAMERP (Research Initiation Scholarship - FAMERP).

This paper was submitted to the RBORL-SGP (Publishing Manager System) on 2 May 2007. Code 4488. The article was accepted on 28 June 2007.
} 


\section{INTRODUCTION}

It is estimated that in developed countries, one child in 750 births presents sensorineural hearing loss, and that one child in each 1,000 births becomes deaf before adulthood. The prevalence increases further and reaches 50\% in octogenarians. ${ }^{1}$ About $60 \%$ of all causes of prelingual hearing loss may be attributed to hereditary factors. Thus, inheritance is becoming more and more relevant in hearing loss and/or deafness. The remaining $40 \%$ are caused by various etiologies. ${ }^{2}$ There are three identifiable possible inheritance patterns in hereditary hearing loss: autosomal recessive, autosomal dominant and X-linked. About 75\% to $85 \%$ of non-syndromic prelingual hearing loss cases manifest as autosomal recessive conditions. Autosomal dominant forms respond for about $15 \%$ to $25 \%$ of cases; the remaining $1 \%$ to $3 \%$ cases are Mendelian inheritance $\mathrm{X}$-linked conditions. There are forms inherited exclusively from the mother - mitochondrial inheritance - in about $0.5 \%$ to $1 \%$ of sensorineural hearing loss of genetic causes; spontaneous mutation may also occur., ${ }^{2,3}$ A relation between mitochondrial disease and hearing loss was established in 1986 based on the study of a patient with mitochondrial myopathy and hearing loss. ${ }^{4}$

Mitochondrial mutations, especially those in the $12 \mathrm{~S}$ rRNA and tRNASer(UCN) genes, are important causes of non-syndromic sensorineural hearing loss in some population groups. ${ }^{5}$ Among these mutations, a substitution of $A->G$ nitrogenated bases in position 1555 of the mitochondrial DNA $12 \mathrm{~S}$ rRNA gene is or particular interest as the main cause of aminoglycoside-induced hearing loss. It was identified in 1993 by a study that described it as a mitochondrial rRNA mutation that led to non-syndromic hearing loss; this was the first molecular genetic analysis of aminoglycoside-induced ototoxicity. ${ }^{6}$

Many studies have suggested that the A1555G mutation by nitrogenated base substitution generates a new pair of C-G bases, making the secondary structure of the human $12 \mathrm{~S}$ rRNA gene strictly similar to the corresponding region of the E. coli 16S rRNA gene; this is referred to as the decoding bacterial rRNA region and an important action site for aminoglycosides. ${ }^{6,7}$ Aminoglycoside binding to the decoding region results in protein translation errors and ensuing bacterial death. When there is a generally homoplasmic mutation altering the human 12S rRNA gene, making its structure similar to that of the bacterial rRNA, aminoglycosides concomitantly bind to cochlear cell mitochondrial DNA, which potentializes its toxic effect in the inner ear, resulting in hearing loss. These studies, therefore, demonstrate the highly specific recognition mode among RNA molecules and aminoglycosides.?

In contrast with systemic mitochondrial mutations, which usually affect only a fraction of all mitochondrial DNA molecules (heteroplasmia), mutations associated with non-syndromic sensorineural hearing loss are generally homoplasmic, and phenotypes may differ considerably among members of the same family, ranging from deep hearing loss to normal hearing. Many factors, such as nuclear genes, mitochondrial DNA haplotypes, environmental factors or tissue-specific factors, may operate independently or in association, and may alter the clinical expression. However, research has not found nuclear modifying genes or correlations among mutations and mitochondrial haplotypes. The only known environmental factors affecting the A1555G mutation are the aminoglycosides. ${ }^{8}$

Although mitochondrial mutations are etiologically relevant in sensorineural hearing loss, few studies have been made in developing countries, especially in Brazil. The purpose of this study, therefore, was to investigate the prevalence of the mitochondrial A1555G mutation in patients with non-syndromic sensorineural hearing loss with and with no exposure to aminoglycosides.

\section{SERIES AND METHOD}

A cross-sectional study was made between September and October 2006 of 20 index cases of non-syndromic sensorineural hearing loss (12 males and 8 females) aged from 1 to 37 years, previously submitted to GJB2 gene and D(GJB6-D13S1830) mutation molecular analysis; the cases had no molecular changes. ${ }^{9}$ The index cases in our sample consisted of 16 sporadic cases (single cases within a family) and four familiar cases (familiar cases). Relatives with hearing loss were also assessed (2 males and 5 females) aged from 5 to 45 years. Thus, 27 hearing loss patients were studied.

A complete history was taken from each patient to investigate the age of onset of hearing loss, other cases in the family, the use of ototoxic drugs (aminoglycosides), and to exclude other environmental causes such as maternal-fetal infections, perinatal complications, meningitis, acoustic trauma and consanguineous marriages. Patients underwent a physical examination (systemic and otorhinolaryngological) and laboratory exams, to exclude syndromic forms of hearing loss (especially craniofacial dimorphism, skin alterations, and branchial, heart and thyroid anomalies, vision disorders, etc.). Other tests were an ophthalmologic evaluation (including fundoscopy), vestibular tests, and temporal bone computed tomography. Thus, a complete clinical assessment was made to exclude patients with hearing loss due to environmental factors except for aminoglycoside use, consanguinity, congenital inner ear malformations and genetic syndromes. Audiological testing consisted of pure tone audiometry, based on which patients with non-syndromic sensorineural hearing loss were included in the study and classified as mild (25-40 dB), moderate (41-60 dB), severe (61-80 dB) or profound $(>81 \mathrm{~dB}){ }^{10}$ 
The patients in the sample were identified as the Hearing Loss Group (HLG) and divided into two subgroups: $(n=13)$.

HLG group I - patients that used aminoglycosides

HLG group II - patients that did not use aminoglycosides $(n=14)$.

One hundred term neonates with one-minute Apgar scores $\geq 7$ and normal otoacoustic emissions tests (done within three days of birth) were selected as the control group (CG).

The Research Ethics Committee of our institution approved this study (protocol $n^{-}$2784/2006). Parents or legal caretakers read and signed a free informed consent form, after which $4.0 \mathrm{ml}$ of whole blood (from a peripheral vein in the HLG group and from the umbilical cord after its ligature in the control group) was taken and placed on a VacutainerÒ tube containing anticoagulant (EDTA). Genomic DNA was extracted from the blood samples of both groups using the GFXTM Genomic Blood DNA Purification Kit (Amersham Pharmacia Biotech Inc.) according to the manufacturer's instructions. Mitochondrial DNA fragments including the mutation region were amplified using the polymerase chain reaction (PCR) technique in a thermocycler (Applied Biosystems - GeneAmp PCR System 9700O) to detect the A1555G mutation. ${ }^{11}$ A pair of primers were synthesized for this reaction and were used to incorporate the deoxynucleotide triphosphates (dNTPs) to initiate DNA amplification, respecting base complementarity (A-T/C-G); mitochondrial DNA was then amplified. Oligonucleotide primer sequences and the conditions for the PCR were in accordance with the literature. ${ }^{11}$

A 643 bp fragment was amplified as a PCR product and then submitted to restriction fragment length polymorphism (RFLP) analysis, using the BsmAI ${ }^{11}$ enzyme (New England Biolabs)Ò during two hours at $55^{\circ} \mathrm{C}$. Enzymatic digestion of normal A1555G mutation sample fragments yields two fragments (413 bp and $230 \mathrm{bp}$ ) as a results of BsmAI enzyme restriction site recognition. Mutation samples yield only the 643 bp fragment, as there is no enzyme site recognition, due to substitution of $A->G$ nitrogenated bases in position 1555 of the mitochondrial DNA.

A second primer pair was also synthesized to amplify a specific cytochrome b region. ${ }^{12}$ This specific region - a highly conserved area of the mitochondrial genome - is used as an internal amplification control to verify the presence of mitochondrial DNA in the samples. The expected size of PCR-amplified fragments using the CitbF and CitbR primers was $161 \mathrm{bp}$. Oligonucleotide primer sequences and the conditions for PCR were in accordance with the literature. $^{12}$

Both primer pairs used in the PCR include regions in the "Human Mitochondrial DNA Revised Cambridge Reference Sequence."13
The products of both reactions (PCR and RFLP) were analyzed using 2\% agarose gel electrophoresis in a TBE 1X buffer containing ethidium bromide, at $0.5 \mathrm{mg} / \mathrm{mL}$ concentration, submitted to ultraviolet light, to confirm the success of the reaction and gel; photographic documentation was done.

\section{Statistical analysis:}

A pilot study was done to assess 100 newborns to estimate the proportion (p) of probable A1555G mutation carriers in the initial sample. The statistical formula "sample size with a known population" was applied to the proportion ( $\mathrm{p}$ ) to obtain the final sample size (n) needed for statistically representing the total population $(\mathrm{Np})$ of newborns born within the study period ( $\mathrm{Np}=352$ neonates). The final sample (n) was calculated using the abovementioned statistical formula with the following parameters: $\mathrm{p}=0.00$ (estimated by the pilot sample); $\mathrm{q}=1.00 ; \mathrm{zc}=3.00$ (99.74\% reliability); $\mathrm{e}=0.03$ (3\% estimated error); $\mathrm{Np}=352$ (population size within the study period).

Formula: $\mathrm{n}=\mathrm{zc}^{2} \times \mathrm{p} \times \mathrm{q} \times \mathrm{N}_{\mathrm{p}}$

$\mathrm{e}^{2} \times(\mathrm{Np}-1) \mathrm{zc}^{2} \times \mathrm{p} \times \mathrm{q}$

Results were expressed as percentages.

\section{RESULTS}

PCR was done for amplification of the b cytochrome gene region to visualize the corresponding $161 \mathrm{bp}$ fragment to confirm the presence of mitochondrial DNA in all 127 samples of the study - 100\% (HLG I and II groups - $n=27$ and the control group - $n=100)$.

PCR enabled amplification of the mitochondrial DNA $643 \mathrm{bp}$ fragment encompassing the mutation area in all of the samples (100\%) of HLG I and II groups $(n=27)$ and the control group $(n=100)$.

The A1555G mitochondrial mutation was not found in the study sample (100\%); 413 bp and 230 bp fragments were found after enzymatic digestion, which were amplified in the absence of mutation in all samples within both groups (HLG I and II groups - n=27 and the control group $-\mathrm{n}=100$ ).

Clinical and audiometric data from the index cases, such as sex, age, onset and degree of hearing loss, use of aminoglycosides and family cases are shown in Chart 1.

\section{DISCUSSION}

Research in population groups in various European countries has found that conexin 26 (Cx26) gene mutations may cause hearing loss in a significant proportion of cases. Continued research has led to the discovery of other mutations, which has made possible molecular etiological identification in many patients; thus, early rehabilitation and genetic counseling have become feasible in these cases. It is interesting to note that the frequency of genes 
Chart 1. Clinical and audiometric data of the 20 index cases in the sample and the 7 affected family members $(n=27)$ that underwent molecular analysis for the detection of the A1555G mitochondrial mutation.

\begin{tabular}{|c|c|c|c|c|c|c|c|c|c|}
\hline $\begin{array}{l}\text { Index case } \\
\text { (IC) }\end{array}$ & Sex & $\begin{array}{c}\text { Age } \\
\text { (Years) }\end{array}$ & $\begin{array}{c}\text { Onset of } \\
\mathrm{HL}\end{array}$ & $\begin{array}{c}\text { Degree of } \\
\mathrm{HL}\end{array}$ & Use of AMG & $\begin{array}{l}\text { Family } \\
\text { Cases }\end{array}$ & $\begin{array}{c}\text { Age } \\
\text { (Years) }\end{array}$ & $\begin{array}{c}\text { Degree of } \\
\mathrm{HL}\end{array}$ & Use of AMG \\
\hline 1 & $\mathrm{~F}$ & 12 & Prelingual & Profound & No & & & & \\
\hline 2 & M & 9 & Prelingual & Severe & Yes & & & & \\
\hline 3 & $\mathrm{~F}$ & 28 & Postlingual & Profound & No & & & & \\
\hline 4 & $\mathrm{~F}$ & 3 & Prelingual & Profound & Yes & & & & \\
\hline 5 & M & 8 & Prelingual & Severe & Yes & & & & \\
\hline 6 & M & 4 & Prelingual & Profound & Yes & & & & \\
\hline 7 & $\mathrm{~F}$ & 10 & Postlingual & Severe & Yes & & & & \\
\hline 8 & $M$ & 7 & Prelingual & Profound & Yes & & & & \\
\hline 9 & M & 3 & Prelingual & Severe & Yes & & & & \\
\hline 10 & $\mathrm{~F}$ & 3 & Prelingual & Profound & Yes & & & & \\
\hline 11 & M & 9 & Prelingual & Profound & Yes & & & & \\
\hline 12 & M & 5 & Prelingual & Profound & Yes & & & & \\
\hline 13 & $\mathrm{~F}$ & 33 & Prelingual & Severe & No & $\begin{array}{c}\text { sister - } 14 \\
\text { brother - } 15 \\
\text { brother - } 16\end{array}$ & $\begin{array}{l}28 \\
37 \\
19\end{array}$ & $\begin{array}{l}\text { Moderate } \\
\text { Profound } \\
\text { Profound }\end{array}$ & $\begin{array}{l}\text { No } \\
\text { No } \\
\text { No }\end{array}$ \\
\hline 17 & M & 37 & Postlingual & Profound & No & & & & \\
\hline 18 & $\mathrm{~F}$ & 5 & Prelingual & Profound & Yes & & & & \\
\hline 19 & M & 10 & Prelingual & Moderate & No & mother - 20 & 38 & Moderate & No \\
\hline 21 & M & 8 & Prelingual & Severe & Yes & & & & \\
\hline 22 & M & 7 & Prelingual & Profound & No & mother - 23 & 45 & Moderate & No \\
\hline 24 & M & 32 & Prelingual & Profound & Yes & & & & \\
\hline 25 & $\mathrm{~F}$ & 10 & Prelingual & Profound & No & $\begin{array}{l}\text { sister - } 26 \\
\text { sister - } 27\end{array}$ & $\begin{array}{l}8 \\
5 \\
\end{array}$ & $\begin{array}{l}\text { Severe } \\
\text { Severe }\end{array}$ & $\begin{array}{l}\text { No } \\
\text { No }\end{array}$ \\
\hline
\end{tabular}

(IC)- Index cases; (M)- Male; (F)- Female; (HL)- Hearing Loss

and mutations that cause hearing loss varies significantly among populations. The $35 \mathrm{del} G$ mutation in the $\mathrm{Cx} 26$ gene, for example, is highly prevalent among deaf persons of European descent,,14 and almost absent in Japanese, Korean or Mongolian individuals. ${ }^{15,16}$

Similarly, the frequency of mitochondrial mutations also differs among populations; the A1555G mutation is found mostly in patients with maternally inherited hearing loss, although it has been sporadically identified in patients with hereditary autosomal recessive conditions. There are major differences in ethnic origin in both transmission modes, as revealed by recent studies showing the mutation to be a frequent cause of non-syndromic hearing loss, associated or not with aminoglycoside use, in Asian, ${ }^{11,17-21}$ Arab, ${ }^{22}$ and South African ${ }^{23}$ populations. It is, however, rare in most of the European and American populations. ${ }^{24,25}$

A study in 32 Asians with hearing loss and in 100 American controls (63 deaf and 37 normal-hearing) found the $\mathrm{A} 1555 \mathrm{G}$ mutation in $87.5 \%$ of Asians that were deaf, and in none of the subjects in the control group, con- cluding that the mutation is not prevalent in non-Asian populations. ${ }^{25}$ This results has been confirmed in a study done in Greece, in which the mutation was absent in 106 cases, ${ }^{26}$ and in another study involving 202 early onset non-syndromic hearing loss patients in the United Kingdom.5 Likewise in our study, the A1555G mitochondrial mutation was not found in the HLG groups (consisting of group I: 13 index cases that had taken aminoglycosides, and group II: 14 index cases that had no prior use of aminoglycosides) and in the control group (100 neonates with normal otoacoustic emissions tests). These results demonstrate that the mutation was not a common cause of hearing loss in our sample.

Two mutation screening program have been done in neonates in the USA. The first of these sampled umbilical cord blood of 1,773 neonates, of which only one carried the mutation. ${ }^{27}$ The second screened 25 neonates that had altered otoacoustic emissions tests, among which the mutation was not found. ${ }^{28}$ Screening of 300 neonates in Argentina and in 712 normal-hearing subjects did not detect the A1555G mutation. ${ }^{29}$ These studies have reported 
low rates in North-American populations, but have not discarded the need for molecular studies in neonatal screening tests, especially in countries where aminoglycosides are used routinely.

Our method has already been described in the literature; 11 it includes amplifying a specific cytochrome $\mathrm{b}$ gene region - a highly conserved mitochondrial genome area - to serve as an amplification control for identifying mitochondrial DNA in all of the samples. ${ }^{12}$ Although the number of cases in both groups was different from the number in some published studies, and although the mutation was not found in both groups (HLG and control groups), we were able to confirm the results of studies that also did not find the mutation in non-Asian or Arab ethnic groups..$^{24-29}$

There is a single study in Brazil reporting the findings of five families with hearing loss cases in which the prevalence of the mutation was $2 \%$ ( 4 cases). Only one of these positive cases was associated with an assumed aminoglycoside exposure; no mutation was found in the control group composed by black, white or Asian (Japanese or Chinese) ethnic groups. ${ }^{30}$ These results - which are different from our study - may be explained by the highly heterogeneous ethnic composition of the Brazilian population that resulted from racial mixing; this may explain prevalence variations in different Brazilian regions.

Many mutations may result in hearing loss; the A1555G mitochondrial mutation, which is related to aminoglycoside use, may be only one of them..$^{17,30}$ Understanding the underlying causes of hearing loss caused by aminoglycoside exposure is essential for therapy - especially in neonatal ICUs - and for genetic counseling and early rehabilitation. This is necessary for including or returning these patients to their social and professional activities.

\section{CONCLUSION}

The PCR/RFLP molecular techniques, such as the protocol we used in this study, are simple methods for tracking the A1555G mutation, supporting the molecular investigation of hearing loss.

There has been considerable interest in establishing the true prevalence of the $\mathrm{A} 1555 \mathrm{G}$ mitochondrial mutation in the Brazilian population by means of molecular testing, as well as investigating other mutations that may result in hearing loss associated or not with aminoglycoside use. These tests may become a valuable adjunct for neonatal audiometric screening.

\section{ACKNOWLEDGEMENTS}

We wish to acknowledge our patients and parents of newborns, without whose approval and cooperation this study would not have been possible. Such contribution is extremely important for the continuity of scientific research and to provide a better future for Brazilian children.

To Cecília Meneguette Ferreira, for her inestimable support.

\section{REFERENCES}

1. American College of Medical Genetics. Genetics Evaluation Guidelines for the Etiologic Diagnosis of Congenital Hearing Loss. Genet Med 2002;4:162-71.

2. Mustafa T, Arnos KS, Pandya A. Advances in hereditary deafness. Lancet 2001;358:1082-90.

3. Denoyelle F, Marlin S, Petit C, Garabédian E-N. Surdités neurosensorielles d'origine génétique. Rev Prat 2000;50:146-9.

4. Petty RKH, Harding AE, Morgan-Hughes JA. The clinical features of mitochondrial myopathy. Brain 1986;109:915-38.

5. Hutchin TP, Thompson KR, Newton V, Bitner-Glindzicz M, Mueller RF. Prevalence of mitochondrial DNA mutations in childhood/congenital onset non-syndromal sensorineural hearing impairment. J Med Genet 2001;38:229-31.

6. Prezant TR, Agapian JV, Bohlman MC, Bu X, Oztas S, Qiu WQ, et al. Mitochondrial ribosomal RNA mutation associated with both antibiotic-induced and non-syndromic deafness. Nat Genet 1993;4:289-94.

7. Hamasaki K \& Rando RR. Specific binding of aminoglycosides to a human rRNA construct based on a DNA polymorphism wich causes aminoglycoside-induced deafness. Biochemistry 1997;36:12323-8.

8. Giordano C, Pallotti F, Walker WF, Checcarelli N, Musumeci O, Santorelli F, et al. Pathogenesis of the deafness-associated A1555G mitochondrial DNA mutation. Biochem Biophys Res Commun 2002;293:521-9.

9. Belintani VP, Goloni-Bertollo EM, Sartorato EL, Maniglia JV. Prevalence of the GJB2 mutations and the del(GJB6-D13S1830) mutation in Brazilian patients with deafness. Hear Res 2004;196:87-93.

10. World Health Organization. Report of the informal working group on prevention of deafness and hearing impairment programme planning. Geneva: WHO, 1991. 22p

11. Noguchi Y, Yashima T, Ito T, Sumi T, Tsuzuku T, Kitamura K. Audiovestibular findings in patients with mitochondrial A1555G mutation. Laryngoscope 2004;114:344-8.

12. Bai U, Seidman MD, Hinojosa R, Quirk WS. Mitochondrial DNA deletions associated with aging and possibly presbicusis: a human archival temporal bone study. Am J Otol 1997;18:449-53.

13. Andrews RM, Kubacha I, Chinnery PF, Lightowlers RN, Turnbull DM, Howell N, 1999. Reanalysis and revision of the Cambridge reference sequence for human mitochondrial DNA. Nat. Genet. 1999; 23(2), 147.

14. Tekin M, Akar N, Cin S, Blanton SH, Xia XJ, Liu XZ, et al. Connexin 26 (GJB2) mutations in the Turkish population: implications for the origin and high frequency of the 35 delG mutation in Caucasians. Human Genet 2001;108:385-9

15. Abe S, Usami S, Shinkawa H, Kelley PM, Kimberling WJ. Prevalent connexin 26 gene (GJB2) mutations in Japanese. J Med Genet 2000;37:41-3.

16. Pandya A, Tekin M, Erdenetungalag R, Xia A, Dangaasuren B, Radnaabazar J, et al. A unique spectrum of alterations in the Cx26 gene in deaf probands from Mongolia. Eur J Hum Genet 2001;9:388.

17. Matsunaga T, Kumanomido H, Shiroma M, Ohtsuka A, Asamura K, Usami S. Deafness due to A1555G mitochondrial mutation without use of aminoglycoside. Laryngoscope 2004;114:1085-90.

18. Matsunaga T Kumanomido H, Shiroma M, Goto Y, Usami S. Audiological features and mitochondrial DNA sequence in a large family carrying mitochondrial A1555G mutation without use of aminoglycoside. Ann Otol Rhinol Laryngol 2005;114:153-60.

19. Tamagawa Y, Kitamura K, Ishida T, Hagiwara H, Abe K, Nishizawa M. Mitochondrial DNA mutation at nucleotide 1555 in a patient with bilateral sensorineural hearing loss of unknown etiology. Acta Otolaryngol 1996;116:796-8. 
20. Malik SG, Pieter N, Sudoyo H, Kadir A, Marzuki S. Prevalence of the mitochondrial DNA A1555G mutation in sensorineural deafness in Island Southeast Asia. J Hum Genet 2003;48:480-3.

21. Pandya A, Xia X, Radnaabazar J, Batsuuri J, Dangaansuren B, FischelGhodsian N, Nance WE. Mutation in the mitochondrial 12S rRNA gene in two families from Mongolia with matrilineal aminoglycoside ototoxicity. J Med Genet 1997;34:169-72.

22. Tekin M, Duman T, Bogoçlu G, Incesulu A, Comak E, Fitoz S, et al Frequency of mtDNA A1555G and A7445G mutations among children with prelingual deafness in Turkey. Eur J Pediatr 2003;162:154-8.

23. Gardner JC, Goliath R, Viljoen D, et al. Familial streptomycin ototoxicity in a South African family: a mitochondrial disorder. J Med Genet 1997;34:904-6.

24. Hutchin T, Cortopassi G. Mitochondrial DNA haplotype predicts deafness risk. AM J Med Genet 1995;60:592

25. Usami S, Abe S, Kasai M, Shinkawa H, Moeller B, Kenyon JB, et al. Genetic and clinical features of sensorineural hearing loss associated with the 1555 mitochondrial mutation. Laryngoscope 1997;107: $438-90$.
26. Kleomitis E, Iliadis T, Voyiatzis N, Economides J, Neou P, Apostolopoulos N, et al. Analysis of the A1555G mtDNA mutation in Greek patients with sensorineural deafness. Am J Hum Genet 2000;67:1879.

27. Tang HY, Hutcheson E, Neil S Drummond-Borg M, Sper M, Alford RL. Genetic susceptibility to aminoglycoside ototoxicity: How many are at risk? Genet Med 2002;4:336-45.

28. Dent KM, Kenneson A, Palumbos JC, Maxwell S, Eichwald J, White $\mathrm{K}$, et al. Methodology of a multistate study of congenital hearing loss: preliminary data from Utah newborn screening. Am J Med Genet C Semin Med Genet 2004;125:28-34.

29. Gravina LP, Foncuberta ME, Estrada RC, Barreiro C, Chertkoff L. Carrier frequency of the $35 \mathrm{delG}$ and $\mathrm{A} 1555 \mathrm{G}$ deafness mutations in the Argentinean population impact on the newborn hearing screening. Int J Pediatr Otorhinolaryngol 2007;4:639-43.

30. Abreu-Silva RS, LezIrovitz K, Braga MCC, Spinelli M, Pirana S, DellaRosa VA, et al. Prevalence of the A1555G (12S rRNA) and tRNASer (UCN) mitochondrial mutations in hearing-impaired Brazilians patients. Braz J Med Biol Res 2006;39:219-26. 